\title{
EDITORIAL
}

For reprint orders, please contact: reprints@futuremedicine.com

\section{Zika virus: an emerging arboviral disease}
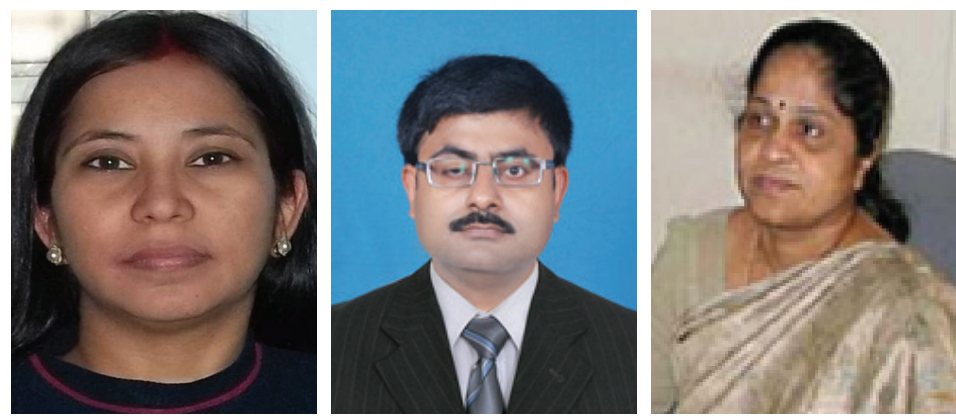

Neelima Arora ${ }^{*, 1}$, Amit K Banerjee ${ }^{2}$ \& Mangamoori Lakshmi Narasu'

First draft submitted: 29 March 2016; Accepted for publication: 5 May 2016;

Published online: 24 May 2016

Few individuals would have heard of Zika virus prior to the current outbreak in the Americas. However, Zika virus is the most recent threat by an arbovirus after chikungunya and dengue outbreaks in this decade. In a very short time span, Zika virus has spread to 66 countries and territories. The WHO declared Zika a public health emergency of international concern (PHEIC) on 1 February 2016 and called for concerted efforts for tackling the situation after an upsurge in the number of microcephaly cases and other neurological disorders in the affected regions [1]. The CDC moved Emergency Operations Center (EOC) to level 1 activation on 8 February 2016 for better coordination and response in curbing Zika virus transmission [2].

\section{Disease outbreaks}

Zika virus is a mosquito-borne Flavivirus belonging to Spondweni serocomplex of family Flaviviridae. Zika virus has two main lineages, African lineage and Asian lineage [3]. Since its first isolation from a monkey in Uganda in 1947 and from a mosquito a year later, several outbreaks have been reported [4]. Before 2007, outbreaks were mainly limited to Africa and Southeast Asia [5]. However, several outbreaks have recently been reported from newer territories outside Zika's known geographical range. The outbreak in Yap Island in Micronesia in 2007 was the first report of the spread of Zika virus outside the region of its origin [6]. Following this, the largest outbreak of Zika virus was reported in Polynesia in late 2013 [7]. Zika virus cases were also reported from Samoa and Solomon Islands, New Caledonia, Fiji and Vanuatu in 2015 [8]. The virus spread to South America in 2015 and has expanded its geographical range since then. The worst hit was Brazil where $0.4-1.3$ million Zika virus cases were reported in 2015 [9]. Approximately 4908 microcephaly cases, which were thought to be Zika associated,

\section{KEYWORDS}

- Aedes aegypti • Aedes albopictus

- Flavivirus • mosquito-borne viral disease $\bullet$ transmission $\bullet$ Zika virus outbreak

"Zika virus is the most recent threat by an arbovirus after chikungunya and dengue outbreaks in this decade." 


\author{
"Understanding the \\ quasi-species structure and \\ dynamics is crucial before \\ devising any strategy \\ against Zika virus.”
}

were reported in Brazil and the number of likely Zika virus cases reached 91,387 within a short period from February 2016 to 2 April 2016 [10]. As of 20 February 2016, Columbia remains the second worst-hit country with 65,338 cases of Zika virus [11]. However, as the disease is not fatal, it did not receive the needed attention in the past. Since a notable increase in infants born with microcephaly was observed during Zika virus outbreak [12], as well as tempo-spatial pattern increase in Guillain-Barré syndrome cases, it is thought there is a possible causal link. This alarming situation has compelled public health researchers to take note and devise effective prevention and control strategies. Zika virus has also been recently identified in six European countries (the UK, Italy, The Netherlands, Portugal, Switzerland and Denmark), however, all the patients had a travel history of visiting countries with ongoing Zika transmission. To date, there is no report of local transmission of Zika in these countries.

\section{Transmission}

The virus circulates mainly in wild primates and Aedes genus of Culicidae family ( $A$. aegypti, A. albopictus, $A$. furcifer, $A$. taylori, $A$. luteocephalus and $A$. africanus), and humans are unintentional, incidental hosts. $A$. aegyti, which transmits dengue and chikungunya, is a competent vector for Zika virus and is responsible for Zika virus transmission outside Africa [13]. Wide distribution of $A$. aegypti and another potential vector, $A$. albopictus, has raised concern over the possibility of global outbreaks. Other potential modes of transmission in humans that have been sporadically reported are through sexual transmission [14,15], blood transfusion [16] and perinatal transmission during delivery $[17,18]$.

\section{Virology}

The Zika virus genome is represented by a single-stranded positive-sense RNA molecule of approximately $10,794 \mathrm{~kb}$ size consisting of 3' untranslated region (UTR) and 5' UTR and open reading frame that encodes a polyprotein that gives rise to three structural proteins; namely capsid, the precursor of the membrane, envelope protein and seven nonstructural proteins, namely: NS1, NS2A, NS2B, NS3, NS4A, NS4B and NS5 [5,19-20]. Sequence heterogeneity and mutation rate, which originate as a result of the lack of a proofreading mechanism due to error-prone viral RNA polymerase and extensive virus multiplication in flaviviruses, result in diverse variants in the virus population present in the host. This complex population structure, consisting of a swarm of various mutant viruses, known as quasispecies, contributes to the adaptability, survival and persistence of viruses, and is considered a major deterrent in vaccine development $[21,22]$. Understanding the quasi-species structure and dynamics is crucial before devising any strategy against Zika virus.

\section{Symptoms \& diagnosis}

Most of the cases of Zika virus are asymptomatic and remain unrecognized. Zika virus symptoms are also confused with other arboviral diseases, such as dengue and chikungunya. These symptoms are mild and flu like, which last for a few days. Zika virus patients mainly suffer from macular papular rash, fever, nonpurulent conjunctivitis, retro-orbital pain, myalgia and arthralgia. As clinical diagnosis of Zika virus is difficult, the availability of robust, rapid and sensitive diagnostic methods is important for the management of Zika virus [23]. Body fluids, such as serum, ethylenediaminetetraacetic acid (EDTA) plasma, saliva and urine are used for diagnosis of Zika virus [24]. Recent studies have suggested the suitability of using urine sample over serum owing to ease of use, noninvasive process, high titers and longer time period [25]. Virus isolation and reverse transcriptase-PCR (RT-PCR) are used for detection of Zika virus in the acute phase, while serological tests and neutralization are used in convalescent phase. Zika virus can be detected by:

- Virus isolation (limited to the first 3-5 days after the onset of symptoms);

- RT-PCR: this is the preferred method for biological confirmation of Zika virus in acutely ill patients [26]. RT-PCR is usually followed by sequencing. The advantages of using RT-PCR for diagnosis are high sensitivity and rapid results, but high cost and a shortage of skilled personnel are important considerations;

- Serological tests, such as immunofluorescence assays and ELISA, for detecting anti-Zika virus IgM and IgG antibodies. However, serological tests often face the problem of crossreactivity with other flaviviruses, hampering differential diagnosis [27];

- Plaque-reduction neutralization testing for differential serodiagnosis of flaviviruses [28]. 
The US FDA approved the diagnostic test CDC Zika IgM Antibody Capture ELISA (Zika MAC-ELISA) under the Emergency Use Authorization (EUA) for presumptive detection of antibodies in blood after 4-5 days from the start of illness [29]. Although the test is not fully accurate and requires careful interpretation of results, it could prove to be a useful aid in surveillance programs. The FDA also recently authorized the CDC's Trioplex RT-PCR assay for detection and differentiation of RNA of Zika, dengue and chikungunya viruses in human sera or cerebrospinal fluid, and for the qualitative detection of Zika virus RNA in urine and amniotic fluid [30].

\section{Treatment \& care}

Currently, no commercial vaccine is available against any Flavivirus, including Zika virus. There is a lack of specific chemotherapeutic agents for the treatment of Zika virus infection. Treatment is limited to antipyretics and analgesics for symptomatic relief. Care should be taken to have ample rest and stay hydrated. In the case of pregnant women with confirmed Zika virus in serum or amniotic fluid, serial ultrasounds are recommended for monitoring proper fetal growth.

\section{Prevention \& control}

In the absence of an available vaccine or chemotherapeutic agent, prevention is the mainstay of the battle against Zika virus. Basic precautions to avoid Zika virus infection are same as those of any mosquito-borne disease. Thus, they rely heavily on two factors:

- Source reduction: this involves removal of breeding sites of the mosquito vector. This can be done by reducing the number of water-filled habitats, such as water containers, by covering water storage tanks and regular cleanups to avoid mosquitoes breeding in empty vases, containers, tires and shells, etc. This approach is more effective with increased awareness and community participation supported by government initiatives (e.g., cleanup drives and insecticide sprays).

- Contact avoidance: this involves preventive measures to prevent against mosquito bites, such as using mosquito repellents with:

- DEET(N,N-Diethyl-meta-toluamide), picaridin or IR3535, wearing appropriate light-colored clothing (e.g., long-sleeved shirts and pants) for minimizing exposed skin areas, using insecticide-treated nets and screening windows to prevent mosquitoes entering rooms.

Novel methods of vector control, such as the release of modified mosquitoes (either genetically modified mosquitoes or irradiated sterile male population) and larval control methods, should be assessed and adopted after careful evaluation of environmental concerns to strengthen the existing programs. Infection of $A$. aegypti with Wolbachia, a naturally occurring endosymbiotic bacterium found in the majority of insect species, is known to interfere with many important life cycle events in mosquitoes, such as reproduction, hatching of eggs, life span and reduced capacity of transmission of dengue [31-33]. Efficacy of use of Wolbachia in preventing dengue transmission was demonstrated in the 'eliminate dengue program' [34]. Wolbachia also inhibits the replication of other arboviruses, for example, chikungunya and yellow fever virus in mosquitoes [35]. Incorporation of this environmentally friendly biological method holds promise and could be tested for combating Zika virus.

\section{Travel advice}

The CDC issued a level 2 warning for pregnant women and all women of childbearing age who may become pregnant against visiting countries with ongoing Zika virus transmission. They also issued travel guidance and recommendations regarding prevention and treatment of Zika virus [36]. Furthermore, they issued interim guidelines, including a 'testing algorithm' [37], to help medical workers treat pregnant women who have recently lived in or traveled to Zika-affected regions.

\section{Conclusion \& future perspective}

The rapid spread of Zika virus is believed to be due to the high density of vector species in urban settings and lack of pre-existing immunity in individuals [38]. International travel due to fast-paced globalization, unplanned urbanization and global climate change are also possible factors. Integrated and multisectoral efforts to increase our arsenal against Zika virus should, therefore, be intensified. The recent launch of a Zika vaccine initiative by NIH could give the necessary boost to the vaccine development process, and many nations have initiated
“Timely interventions for reducing the Aedes population by destruction or modification of vector habitat will aid in reducing the dengue burden, as well as help prevent Zika virus outbreak.” 
campaigns to accelerate research on this front. Many biotech pharma companies are also expediting the vaccine development process. In addition, vector surveillance and control measures should be strengthened and scaled up in affected regions to monitor Zika virus transmission [11]. Development and evaluation of novel methods to control vector population should be prioritized.

Developing nations in the tropical belt face the enormous burden of mosquito-borne diseases every year. The risk of Zika virus spread in South Asia, owing to the presence of vector mosquitoes, has set the alarm ringing and, thus, it is important to scale up surveillance and control programs. Approved insecticidal sprays should be regularly used and cleanliness drive to eliminate habitat for vector mosquitoes should now be carried out. Awareness campaigns should be conducted to educate practitioners and the general public for better outcomes in the event of an outbreak. Timely interventions for reducing the Aedes population by destruction or modification of vector habitat will aid in reducing the dengue burden, as well as help prevent Zika virus outbreak. These steps will aid in preventing the pandemic from affecting new territories; action is needed now before it is too late.

\section{Acknowledgements}

$N$ Arora would like to thank the University Grants Commission for Dr DS Kothari Postdoctoral Fellowship.

\section{Financial \& competing interests disclosure}

The authors have no relevant affiliations or financial involvement with any organization or entity with a financial interest in or financial conflict with the subject matter or materials discussed in the manuscript. This includes employment, consultancies, honoraria, stock ownership or options, expert testimony, grants or patents received or pending, or royalties.

No writing assistance was utilized in the production of this manuscript.

\section{References}

1 CDC. CDC Emergency Operations Center moves to highest level of activation for Zika response.

www.cdc.gov

2 WHO. WHO Director-General summarizes the outcome of the Emergency Committee regarding clusters of microcephaly and Guillain-Barré syndrome. www.who.int

3 Haddow AD, Schuh AJ, Yasuda CY et al. Genetic characterization of Zika virus strains: geographic expansion of the Asian lineage. PLoS Negl. Trop. Dis. 6(2), e1477 (2012).

4 Dick GW, Kitchen SF, Haddow AJ. Zika virus. I. Isolations and serological specificity. Trans. R. Soc. Trop. Med. Hyg. 46, 509-520 (1952).

5 Lanciotti RS, Kosoy OL, Laven JJ et al. Genetic and serologic properties of Zika virus associated with an epidemic, Yap State, Micronesia, 2007. Emerg. Infect. Dis. 14, 1232-1239 (2008).

6 Duffy MR, Chen TH, Hancock WT et al. Zika virus outbreak on Yap Island, Federated States of Micronesia. N. Engl. J. Med. 360, 2536-2543 (2009).

7 Cao-Lormeau VM, Roche C, Teissier A et al. Zika virus, French Polynesia, South Pacific, 2013 (letter). Emerg. Infect. Dis. 20(6), 1085-1086 (2014).

8 Craig AT, Butler MT, Pastore R, Paterson B, Durrheim DN. Update on Zika virus transmission in the Pacific islands, 2007 to
February 2016 and failure of acute flaccid paralysis surveillance to signal Zika emergence in this setting. Bull. World Health Organ. doi: 10.2471/BLT.16.171892 (2016) (Epub ahead of print).

9 Zika virus microcephaly and Guillain-Barré syndrome situation report 26 February 2016. www.who.int

10 Reuters. Brazil says Zika-linked microcephaly cases stable at 4908 . www.reuters.com

11 WHO. Zika virus microcephaly and Guillain-Barré syndrome situation report. http://apps.who.int

12 Butler D. Zika virus: Brazil's surge in small-headed babies questioned by report. Nature 530, 13-14 (2016).

13 Li MI, Wong PS, Ng LC, Tan CH. Oral susceptibility of Singapore Aedes (Stegomyia) aegypti (Linnaeus) to Zika virus. PLoS Negl. Trop. Dis. 6(8), e1792 (2012).

14 Musso D, Roche C, Robin E, Nhan T, Teissier A, Cao-Lormeau VM. Potential sexual transmission of Zika virus. Emerg. Infect. Dis. 21, 359-361 (2015).

15 McCarthy M. Zika virus was transmitted by sexual contact in Texas, health officials report. BMJ 352, i720 (2016).

16 Marano G, Pupella S, Vaglio S, Liumbruno GM, Grazzini G. Zika virus and the never-ending story of emerging pathogens and transfusion medicine. Blood Transfus. 1-6 (2015).
17 Besnard M, Lastere S, Teissier A, CaoLormeau V, Musso D. Evidence of perinatal transmission of Zika virus, French Polynesia, December 2013 and February 2014. Euro Surveill. 19(13), pii: 20751 (2014).

18 Oliveira Melo AS, Malinger G, Ximenes R et al. Zika virus intrauterine infection causes fetal brain abnormality and microcephaly: tip of the iceberg? Ultrasound Obstet. Gynecol. 47, 6-7 (2016).

19 Chambers TJ, Hahn CS, Galler R et al. Flavivirus genome organization, expression, and replication. Annu. Rev. Microbiol. 44, 649-668 (1990).

20 Baronti C, Piorkowski G, Charrel RN et al. Complete coding sequence of Zika virus from a French Polynesia outbreak in 2013. Genome Announc. 2(3), e00500-e00514 (2014).

21 Lauring AS, Andino R. Quasispecies theory and the behavior of RNA viruses. PLoS Pathog. 6(7), e1001005 (2010).

22 Kurosu T. Quasispecies of dengue virus. Trop. Med. Health 39(Suppl. 4), 29-36 (2011).

23 Zumla A, Goodfellow I, Kasolo F et al. Zika virus outbreak and the case for building effective and sustainable rapid diagnostics laboratory capacity globally. Int. J. Infect. Dis. 4(45), 92-94 (2016).

24 Charrel RN, Leparc-Goffart I, Pas S, de Lamballerie X, Koopmans M, Reusken C. State of knowledge on Zika virus for an adequate laboratory response. Bull. World 
Health Organ. E-pub doi: 10.2471/ BLT.16.171207 (2016) (Epub ahead of print).

Gourinat AC, O'Connor O, Calvez E, Goarant C, Dupont-Rouzeyrol M. Detection of Zika virus in urine. Emergi. Infect. Dis. 21(1), 84-86 (2015).

26 Faye O, Faye O, Diallo D, Diallo M, Weidmann M, Sall AA. Quantitative real-time PCR detection of Zika virus and evaluation with field-caught mosquitoes. Virol. J. 10, 311 (2013).

27 Foy BD, Kobylinski KC, Foy JLC et al. Probable non-vector-borne transmission of Zika virus, Colorado, USA. Emerg. Infect. Dis. 17, 880-882 (2011).

28 Maeda A, Maeda J. Review of diagnostic plaque reduction neutralization tests for Flavivirus infection. Vet. J. 195(1), 33-40 (2013).
29 US FDA. Emergency use authorizations. www.fda.gov

30 CDC. New CDC laboratory test for Zika virus authorized for emergency use by FDA. www.cdc.gov

31 Ferguson NM, Kien DT, Clapham $\mathrm{H}$ et al. Modeling the impact on virus transmission of Wolbachia-mediated blocking of dengue virus infection of Aedes aegypti. Sci. Transl. Med. 7(279), 279ra37 (2015).

32 Hoffmann AA, Montgomery BL, Popovici J et al. Successful establishment of Wolbachia in Aedes populations to suppress dengue transmission. Nature 476(7361), 454-457 (2011).

33 Bull JJ, Turelli M. Wolbachia versus dengue. Evolutionary forecasts. Evol. Med. Public Health 2013(1), 197-207 (2013).
34 Walker T, Johnson PH, Moreira LA et al. The wMel Wolbachia strain blocks dengue and invades caged Aedes aegypti populations. Nature 476 (7361), 450-453(2011).

35 Yakob L, Walker T. Zika virus outbreak in the Americas: the need for novel mosquito control methods. Lancet Glob. Health 4(3), e148-e149 (2016).

36 CDC. Recognizing, managing, and reporting Zika virus infections in travelers returning from Central America, South America, the Caribbean, and Mexico.

http://emergency.cdc.gov/han/han00385.asp

37 CDC. Interim guidance. www.cdc.gov

38 Ai JW, Zhang Y, Zhang W. Zika virus outbreak: 'a perfect storm'. Emerg. Microbes Infect. 5(3), e21 (2016). 